\title{
Phraseology of the Cultural Dimension
}

\section{[La fraseología desde la dimensión cultural]}

\author{
Anna Zholobova
}

\section{DOI: 10.18355/XL.2015.08.01.11-27}

\section{Resumen}

El artículo está dedicado al estudio de la compleja relación entre la fraseología y la cultura. El objetivo del artículo es establecer la tipología de los fenómenos culturales reflejados en la fraseología tanto española como rusa, y revelar los factores que influyen en la interpretación del significado de las unidades fraseológicas culturalmente marcados como son, por ejemplo, las frases hechas de origen bíblico, para lo cual se analizan los resultados de dos encuestas realizadas con los estudiantes rusos y españoles.

Palabras clave

fraseología, cultura, culturema, bibleísmos fraseológicos

\section{Introducción}

En la fraseología se refleja en gran medida la vida en todas sus vertientes, el "espíritu" del pueblo, como decía Wilhelm von Humboldt, ahora diríamos que se refleja la cultura. Existen numerosas definiciones del término cultura, pero no es el lugar apropiado para hacer indagaciones acerca de este concepto. Sin embargo, podemos aceptar la definición sencilla que proponen Dobrovol'skij y Piirainen: "Culture is the sum of all ideas about the world (including fictional, mythological etc. ideas) that are caracteristic of a given community" (Dobrovol'skij y Piirainen, 2005: 213). Como señala Teliya, el conjunto de las imágenes fijadas en la fraseología de una lengua sirve de una especie de "nicho" para acumular las ideas sobre el mundo [мировидение], y, de un modo u otro, está relacionado con la cultura material, social o espiritual de la comunidad lingüística en cuestión, por lo cual puede poner en evidencia su experiencia cultural-nacional y sus tradiciones (Teliya, 1996: 215). Por otro lado, cabe señalar la relación recíproca que existe entre la lengua y la cultura, puesto que la lengua, al ser "almacén" de los conocimientos culturales, a su vez, influye en la mentalidad al nivel colectivo y también individual y, en cierta medida, la acuña.

\section{Fenómenos culturales reflejados en la fraseología}

Ahora bien, los fenómenos culturales en sí mismos presentan mucha diversidad, lo cual también, lógicamente, se plasma en la fraseología de cada lengua en concreto. Luque Durán, por ejemplo, divide los fenómenos culturales que han evocado las UFs en cuatro apartados: a) tópicos bíblicos; b) tópicos clásicos (de la tradición greco-latina o cultura común europea); c) tópicos nacionales (tradiciones, juegos, instituciones, etc.); d) tópicos raciales, prejuicios (Luque Durán, 1996).

Nos gustaría detenernos en la tipología de los fenómenos culturales que proponen Dobrovol'skij y Piirainen. Los distinguidos lingüistas destacan cinco aspectos del conocimiento cultural, a saber:

1. aspectos sociales de la cultura;

2. aspectos de la cultura material;

3. fenómenos intertextuales;

4. dominios conceptuales ficticios; 
5. símbolos culturales.

Los aspectos sociales de la cultura engloban los llamados modelos sociales, tabús, eufemismos (estirar la pata), gestos (tirarse de los pelos), especificaciones sexistas (llevar los pantalones), etc., es decir, todo lo que tiene que ver con el comportamiento e interacción social. Normalmente, las unidades fraseológicas (UFs, en adelante) prototípicas son refranes que expresan normas sociales (por ejemplo, a quien madruga Dios le ayuda). Creemos que en el mismo dominio nosotros podríamos incluir las UFs que están relacionadas con la vida profesional del pueblo y las costumbres populares, aunque Dobrovol'skij y Piirainen no lo mencionan:

- $\quad$ tradiciones y costumbres del pueblo:

- la UF rusa мало каши ел "ha comido poca gacha" se aplica a una persona físicamente débil o muy joven (kasha es un plato tradicional ruso que se prepara con cereales; se les da, sobre todo, a los niños, ya que este alimento sólido facilita su crecimiento);

- la UF española arrimar el ascua a su sardina se emplea hablando de egoísmo (era costumbre de los braceros del campo andaluz asar al aire libre y en derredor de una fogata las sardinas de yantar, para lo cual cada uno tomaba del fuego un ascua e iba arrimando a ella la sardina) (Junceda, 2006);

- $\quad$ vida profesional del pueblo:

- la UF rusa тянуть канитель "estirar el cañutillo" se dice de un asunto demasiado lento, la pérdida de tiempo (se trata de un oficio antiguo; antaño los hilos de oro o plata se elaboraban manualmente. Se calentaba el metal y luego se estiraba muy lentamente un hilo finísimo);

- la UF rusa лька не вяжет "uno no lía el líber" se aplica a una persona muy borracha (se refiere al oficio tradicional antiguo de hacer zapatos, cestas, cuencos del líber);

- $\quad$ la UF española como hacer mangas y capirotes 'hacer alguien lo que le da la gana; no hacer caso a nadie; hacer algo precipitadamente, sin poner atención' (el término manga designa a los instrumentos utilizados en repostería para poner crema o nata; los capirotes son las caperuzas de los nazarenos. Ambos tienen la misma forma y nada se hace de manera más rápida y sencilla) (Buitrago, 2007);

- la UF española cortarse la coleta 'jubilarse, retirarse de cualquiera profesión' (es costumbre entre los toreros cortarse en público simbólicamente la coleta en la última corrida que torean) (Buitrago, 2007).

Como lo hemos podido comprobar, la tipología vista más arriba no abarca las UFs que están relacionadas con la historia nacional. Por lo cual, creemos que lo suyo sería llamar al primer tipo de fenómenos culturales aspectos histórico-sociales, que están estrechamente ligados. Entre los ejemplos podemos mencionar los siguientes:

- la UF rusa потемкинские деревни "los pueblos de Potemkin" significa 'lujo, bienestar aparente, falso': Potemkin era un príncipe ruso en los tiempos de la emperatriz Catarina II. Según cuentan, Potemkin ordenó construir unos pueblos falsos con bonitas casitas en la zona que estaba bajo su subordinación para demostrarle el bienestar de esa región a la emperatriz que estaba de viaje por Rusia.

- la UF rusa попасть в кабалу "caer en la gabela" 'caer en la esclavitud': Kabalá era un documento jurídico sobre préstamos y empeños en la época de la Rusia Antigua, según el cual, si el deudor no devolvía su deuda, se convertía en esclavo.

- la UF española artificio de Juanelo 'idea ingeniosa y sencilla mediante la cual viene a resolverse alguna dificultad inveterada': hace alusión al 
relojero e ingeniero hidráulico italiano Juanelo Turriano, que realizó muchas obras de ingenio mecánico al servicio de Carlos V y Felipe II (Celdrán Gomariz, 2004).

- la UF española armar la de San Quintín 'armar un gran escándalo' alude a la batalla que tuvo lugar el 10 de agosto de 1557 y en la que las tropas de Felipe II, comandadas por Manuel Filiberto de Saboya, ocuparon la ciudad francesa de San Quintín, derrotando a las tropas francesas (Buitrago, 2007).

En cuanto a la cultura material, ésta comprende artefactos, ropa, comida, bebida, etc. tradicionales. Por ejemplo, la UF rusa бесструнная балалайка "balalaica sin cuerdas" 'una persona que habla sin parar, cotorra' (balalaica es un instrumento tradicional ruso); la UF española cortar el bacalao 'llevar la iniciativa, mandar y disponer' (hubo una época en la que el bacalao seco era uno de los alimentos básicos de las clases populares sobre todo en el siglo XIX y primera mitad del XX, particularmente durante la Cuaresma. En la familia, el padre era quien lo cortaba y lo repartía) (Celdrán Gomariz, 2004).

Los fenómenos intertextuales comprenden dos tipos: las citas y las alusiones que proceden de la literatura nacional, películas, canciones, publicidad, mitología y literatura clásica, historia. Como ejemplos del primer tipo (las citas), podemos citar la UF rusa смешенье франиузского с нижегородским "mezcla de la lengua francesa con la de Nizhnij Novgorod" se aplica al habla incorrecta (es cita de la obra de A.S. Griboyedov "Desdichado por ser inteligente" (1822-1824); se refiere a que en el siglo XIX la gente aristócrata rusa solía hablar francés, a menudo, muy mal), y la UF española la alegría de la huerta 'persona que siempre muestra alegría y buen humor' es el título de una famosa zarzuela ambientada en la huerta murciana, de Enrique García Álvarez y Antonio Paso (Buitrago, 2007).

En cuanto al segundo tipo (las alusiones), podemos mencionar la UF rusa подковать блоху "herrar la pulga" que significa "demostrar ingeniosidad en tratar algún asunto' (la expresión debe su origen al relato de N.S. Leskov "El zurdo" (1881). Se cuenta que los ingleses hicieron una pulga minuciosa de metal y la enviaron como regalo al zar ruso para demostrar el arte de sus artesanos. Sin embargo, un artesano ruso llamado Zurdo consiguió herrar la pulga, el resultado de su trabajo se pudo ver sólo con un microscopio potente). Para el español, podemos mencionar la UF española luchar contra los molinos de viento 'intentar tenazmente conseguir algo que parece muy difícil o imposible, o discutir con alguien con quien no se puede razonar' (la frase hace alusión al episodio más conocido de El Quijote cuando Don Quijote entra en batalla contra unos molinos de viento, creyéndolos gigantes).

Los dominios conceptuales ficticios engloban todo tipo de creencias, supersticiones, folklore, religión, etc. Por ejemplo, la UF rusa избушка на курьих ножках "casita con las patas de gallina" se aplica a cualquiera construcción de madera pequeña y vieja (la expresión se refiere a la morada de la bruja llamada BabaYaga que aparece en muchos cuentos folclóricos rusos); la UF rusa живая вода "agua viva" significa 'todo lo que da energía y fuerzas a la persona' (en los cuentos rusos, es el agua milagrosa que resucita a los muertos; también existe мертвая вода "agua muerta" que tiene un poder curativo).

Para el español, podríamos citar la UF más viejo/ feo que Carracuca (Carracuca es un personaje folclórico cuyo nombre deriva de la palabra carraco; en el Hospital General de Madrid en el siglo XVIII existió una sala de los carracos, destinada a los enfermos cuyo mal era la mucha edad) (Celdrán Gomariz, 2004); otra UF podría ser no tener dos dedos de frente 'no tener sentido común, ser muy torpe' (antiguamente, se pensaba que la inteligencia dependía de la configuración de la frente hasta el punto de pensarse que todos a los que les llegaba el pelo hasta las cejas eran torpes o ignorantes) (Buitrago, 2007). 
Los símbolos culturales se reducen a un solo componente de la UF; el enlace motivacional entre la lectura literal y la figurativa se establece a partir del conocimiento semiótico acerca del símbolo en cuestión. Por ejemplo, PAN no solo en la cultura española, sino, por lo menos, en la europea, simboliza subsistencia, bondad (Pamies, 2007).

La teoría de Dobrovol'skij y Piirainen, sobre todo la teoría de los símbolos culturales, ha tenido gran impacto en la lingüística. Así, en la Universidad de Granada se está desarrollando y llevando a cabo un proyecto muy prometedor del diccionario interlingüístico intercultural a partir del análisis semántico cognitivo-cultural (Pamies, 2007, 2009; Luque Durán, 2007; Luque Nadal, 2007, 2009 y otros). La noción clave de dicho proyecto es la de culturema que se refiere a "aquellos símbolos que tienen una demostrada huella en el léxico figurado: son extralingüísticos en su origen pero verbalizados a partir de un simbolismo previo" (Pamies, 2009: 230).

Luque Nadal define el término culturema de la siguiente manera: "cualquier elemento simbólico específico cultural, simple o complejo, que corresponda a un objeto, idea, actividad o hecho, que sea suficientemente conocido entre los miembros de una sociedad, que tenga valor simbólico y sirva de guía, referencia, o modelo de interpretación o acción para los miembros de dicha sociedad" (Luque Nadal, 2009: 97). Asimismo, propone cuatro criterios para diferenciarlo de otros fenómenos culturales:

1. vitalidad, figuratividad y motivación

2. productividad fraseológica

3. frecuencia de aparición en alusiones textuales, variaciones, explotaciones, chistes, etc.

4. complejidad estructural y simbólica (Luque Nadal, 2009).

Hablando de los símbolos, Baranov y Dobrovol'skij distinguen entre cuatro grupos de categorías simbólicas (2009). Es evidente que solamente las últimas tres categorías están presentes en el campo de fraseología y reciben el nombre de entidades materiales (Baranov y Dobrovol'skij, 2009: 212).

1. los símbolos culturales: son símbolos propiamente dichos, no están presentes en las funciones simbólicas del sistema léxico de la lengua (por ejemplo, CRÁNEO Y HUESOS es un símbolo de un peligro mortal).

2. los símbolos lingüísticos: son entidades fijadas por la lengua (ya citado el ejemplo de PAN como símbolo de subsistencia se refleja en las UFs ganarse el pan, quitarle el pan de la boca a alguien, comer el pan de alguien, sin embargo, pan como alimento no es un símbolo representado extralingüísticamente, como en el caso anterior).

3. los símbolos en sentido fuerte: son símbolos culturales y lingüísticos al mismo tiempo (por ejemplo, CRUZ, por un lado, es un símbolo del cristianismo y de sufrimiento, y, por otro, está verbalizado, como lo demuestran las UFs llevar su cruz, cargar con una cruz, andar con la cruz a cuestas).

4. los símbolos lingüísticos no-productivos: están presentes en la lengua en una cantidad muy restringida de formas, creando un potencial simbólico del sistema lingüístico (en la UF rusa погнаться за двумя зайцами "echarse a correr detrás de dos liebres" el componente заяц "liebre" se asocia con idea de un objetivo, aunque "liebre" no sea símbolo de objetivo).

Para distinguir entre los símbolos propiamente dichos y los símbolos lingüísticos, Teliya aplica el término cuasisímbolo (Teliya, 1996: 243), ya que en el último caso no es un objeto, artefacto o persona, sino que el nombre adquiere una función simbólica. El significado del componente simbólico no apunta a su referente, sino reemplaza una u otra idea por asociación. 
Aparte de los cinco dominios, Dobrovol'skij y Piirainen (2005) distinguen las connotaciones culturales que son características de las UFs con nombres propios y sus derivados, personajes folklóricos, palabras que denotan realias idioétnicas, etc., es decir, de las UFs que hablantes nativos perciben como específicas de su propia cultura nacional. Casi todos los ejemplos que hemos visto más arriba tienen connotaciones culturales.

Además de las UFs propias de la lengua, podemos también decir, propias de la cultura en cuestión, se puede distinguir las UFs préstamos, es decir, las UFs que reflejan los fenómenos de la cultura ajena. En cuanto a la migración fraseológica debido a los contactos internacionales e interlingüísticos, se distingue entre tres mecanismos principales: los calcos (la formación de unidades fraseológicas por vía de la reproducción semántica, la estructura morfosintáctica y la composición léxicosemántica de las UFs de otra lengua), los préstamos directos, es decir, las unidades fraseológicas cogidas de otra lengua sin traducción -por ejemplo, rus. альма матер 'universidad' del latín alma mater; esp. ad libitum 'a gusto, a voluntad' del latín- y los llamados préstamos semánticos (Soloduxo, 1989).

Como ejemplo de los calcos fraseológicos, podemos mencionar la UF rusa пятая колонна calcada de la UF española la quinta columna que se originó en el ámbito de la guerra civil española para designar al núcleo de fuerza clandestina que operaba infiltradamente desde las filas del ejército republicano. El autor es el general Queipo de Llano, quien informó desde la Radio Sevilla acerca del avance de las tropas nacionales sobre la capital y cifró los efectivos de ataque en cuatro columnas, más una quinta que operaba secretamente en el inferior de Madrid. Desde entonces la frase se aplica a todo grupo bélico de acción clandestina infiltrado en las filas enemigas (Junceda, 2006).

Cuando hablamos de los préstamos semánticos, nos referimos a los préstamos en sentido bastante amplio, ya que estas unidades reflejan la realidad extralingüística surgiendo en las lenguas de muchos pueblos a base de ideas, imágenes, mitos, acontecimientos, etc. de otros pueblos. Las fuentes más importantes de este grupo de las UFs son, por un lado, la literatura, la historia y la mitología antigua clásica, y, por otro, la Biblia. A continuación ofrecemos unos ejemplos del primer tipo de las UFs: la UF esp. el talón de Aquiles / rus. Ахилесова пята con significado 'punto vulnerable' refleja la historia del héroe de la mitología griega Aquiles quien de pequeño fue bañado en el río sagrado para que se hiciera invulnerable. Pero la única parte de su cuerpo que no recibió este poder fue su talón, ya que su madre, la diosa del mar, al bañar a Aquiles lo sujetaba por el talón. Durante la guerra de Troya, Aquiles fue matado por la flecha que atravesó su talón (Buitrago, 2007); la UF esp. entre Escila y Caribdis / rus. между Сцилой и Харибдой 'entre dos peligros graves' hace referencia al viaje de Ulises cuando se encuentra dos veces entre Escila y Caribdis y consigue salvarse, como nos cuenta Homero en la Odisea. Según la mitología griega, Escila y Caribdis eran dos terribles monstruos que habitaban en el estrecho de Mesina, entre la Península Itálica y Sicilia, y que destruían los barcos (Buitrago, 2007).

La Biblia es, quizás, la fuente cultural más importante de la fraseología dando origen a numerosas expresiones fijas en todas las lenguas europeas. Por lo tanto, hemos decidido dedicar más atención a los bibleísmos fraseológicos exponiendo aquí los resultados de dos encuestas realizadas en la Universidad de Granada (España) y la Universidad de Kazán (Rusia). 


\section{Bibleísmos fraseológicos: su interpretación por los hablantes nativos $y$ extranjeros \\ 3.1 Encuesta realizada en la Universidad de Granada}

Para la encuesta realizada con 88 alumnos de filología de la Universidad de Granada, hemos elegido 89 expresiones de origen bíblico. Los objetivos de la encuesta era establecer las UFB más y menos conocidas y explicar el significado de las UFB. En la tabla que sigue, exponemos los resultados de la encuesta: las UFB están en el orden descendente desde las más conocidas hasta las desconocidas por parte de los estudiantes.

\begin{tabular}{|l|c|}
\hline \multicolumn{1}{|c|}{ UFB } & Total respuestas \\
\hline A imagen y semejanza & $99 \%$ \\
\hline Más viejo que Matusalén & $98 \%$ \\
\hline El pan nuestro de cada día & $95 \%$ \\
\hline Traer a alguien por la calle de la amargura & $94 \%$ \\
\hline Poner/ meter/ colocar el dedo en la llaga & $92 \%$ \\
\hline La oveja descarriada & $89 \%$ \\
\hline Ver el cielo abierto & $88 \%$ \\
\hline Estar hecho/ parecer un adefesio & $85 \%$ \\
\hline Llevar alguien su cruz & $78 \%$ \\
\hline Niña de los ojos & $73 \%$ \\
\hline Estar hecho/ parecer un Judas & $72 \%$ \\
\hline Espada de doble filo & $70 \%$ \\
\hline Llorar lágrimas de sangre & $68 \%$ \\
\hline Valle de lágrimas & $64 \%$ \\
\hline Ser/ parecer/ estar hecho una Magdalena & $64 \%$ \\
\hline El buen samaritano & $63 \%$ \\
\hline Armar(se)/ montar(se) un/ el belén & $61 \%$ \\
\hline Pasar las vacas flacas & $61 \%$ \\
\hline Ver la paja en el ojo ajeno & $59 \%$ \\
\hline Ser un Sansón & $58 \%$ \\
\hline Predicar/ clamar/ dar voces en el desierto & $55 \%$ \\
\hline Pobre de espíritu & $52 \%$ \\
\hline Rollo macabeo & $52 \%$ \\
\hline David y Goliath & $47 \%$ \\
\hline Pasar las vacas gordas & $47 \%$ \\
\hline Subírsele a uno el humo a las narices & $47 \%$ \\
\hline Sacar agua de las piedras & $44 \%$ \\
\hline Echar margaritas/ perlas a los cerdos & $40 \%$ \\
\hline (El) alfa y omega & $40 \%$ \\
\hline Donde Cristo dio las tres voces & $38 \%$ \\
\hline Nadie es profeta en su tierra & $35 \%$ \\
\hline Construir/ edificar en/ sobre la arena & $35 \%$ \\
\hline Hablar adefesios & $35 \%$ \\
\hline Sodoma y Gomorra & $34 \%$ \\
\hline Meterse en un belén/ en belenes & $34 \%$ \\
\hline Meterse/ entrar/ pasar por el ojo de una aguja & \\
\hline La torre de Babel & $28 \%$ \\
\hline Decisión/ sentencia salomónica & \\
\hline No tener a donde volver la cara & $31 \%$ \\
\hline Ser de la piel de Barrabás & \\
\hline
\end{tabular}




\begin{tabular}{|c|c|}
\hline El chivo expiatorio & $27 \%$ \\
\hline Donde Sansón perdió el flequillo & $27 \%$ \\
\hline Pegársele a alguien la lengua al paladar & $24 \%$ \\
\hline Estar hecho un eccehomo/ un nazareno & $24 \%$ \\
\hline Negar alguna cosa como san Pedro & $23 \%$ \\
\hline Ir de Herodes a Pilatos & $23 \%$ \\
\hline Separar el trigo de la cizaña & $20 \%$ \\
\hline La piedra angular & $19 \%$ \\
\hline Ser un edén & $19 \%$ \\
\hline El arca de Noé & $18 \%$ \\
\hline La costilla de Adán & $18 \%$ \\
\hline Tener los pies de barro & $18 \%$ \\
\hline Estar hecho/ parecer un Adán & $18 \%$ \\
\hline No ser digno de atarle los cordones de los zapatos & $17 \%$ \\
\hline Adorar al becerro de oro & $15 \%$ \\
\hline Gigante/ coloso con pies de barro & $15 \%$ \\
\hline Maná caído del cielo & $14 \%$ \\
\hline Entrar/ meter en el redil & $13 \%$ \\
\hline La voz que clama en el desierto & $11 \%$ \\
\hline Masacre de inocentes & $11 \%$ \\
\hline No estar/ está la Magdalena para tafetanes & $11 \%$ \\
\hline La sal de la tierra & $10 \%$ \\
\hline La travesía del desierto & $9 \%$ \\
\hline Sepulcro blanqueado & $9 \%$ \\
\hline La ley/ pena del talión & $8 \%$ \\
\hline Tierra de promisión/ tierra prometida & $7 \%$ \\
\hline Armar(se)/ preparar(se) un expolio & $7 \%$ \\
\hline Ser/ parecer un Jeremías & $7 \%$ \\
\hline El festín/ el banquete/ la cena de Baltasar & $6 \%$ \\
\hline Apurar/ beber(se) el cáliz hasta las heces & $5 \%$ \\
\hline Dar coces contra el aguijón & $5 \%$ \\
\hline Ser peor que Géstas & $5 \%$ \\
\hline Armarse un toletole & $5 \%$ \\
\hline Convertir en una estatua de sal & $3 \%$ \\
\hline Ser el Cirineo (de una persona) & $3 \%$ \\
\hline Estar en/ ir por el camino de Emaús & $3 \%$ \\
\hline Sacudir el polvo de los pies & $2 \%$ \\
\hline Trampa saducea & $2 \%$ \\
\hline La piedra de escándalo & $2 \%$ \\
\hline Estar en el camino de Damasco & $1 \%$ \\
\hline Estar/ estar bailando en Belén & $1 \%$ \\
\hline Pagar alguien con las setenas algo & $1 \%$ \\
\hline Carta de Urías & $1 \%$ \\
\hline Las ollas de Egipto (desear, recordar, volver) & $1 \%$ \\
\hline Bañarse en el río Jordán & $0 \%$ \\
\hline Seno de Abraham & $0 \%$ \\
\hline La ida del cuervo & $0 \%$ \\
\hline Ser como/ parecer la burra de Balaam & $0 \%$ \\
\hline
\end{tabular}

Relación de las UFB según el grado de conocimiento.

17

XLinguae Journal, Volume 8 Issue 1, January 2015, ISSN 1337-8384 
El hecho de haber oído o, incluso, usado una expresión no quiere decir que se conozca bien su significado real. A continuación presentamos algunas respuestas que nos han parecido interesantes, puesto que demuestran interpretación personal bastante variada, a menudo errónea, de los significados de las UFB. Además, nos parece que en algunos casos, sin conocer las expresiones, los encuestados han intentado deducir el significado de la UFB a partir de la imagen subyacente o asociaciones. Los significados reales de las expresiones fijas están entre los paréntesis. Adorar al becerro de oro ('interesarse sólo por los bienes materiales'): 'hacer algo indebido', 'hacer algo inequívoco'.

(el) Alfa y omega (1. 'polos extremos de algo'; 2. 'la esencia, la base de algo, lo más importante'): 'lo contrario', 'ser de una manera y de otra distinta a la vez', 'serlo todo, omnipotente', 'ser la noche y el día, algo totalmente diferente', 'ser el líder o el menos importante de todos'.

Apurar/beberse el cáliz hasta las heces ('sufrir todo tipo de penalidades, pasar por grandes sufrimientos'): 'dejar algo totalmente terminado'.

Armar(se)/ montar(se) un/ el belén ('montar un escándalo, jaleo'): 'cuando durante un período muy corto de tiempo se ha ganado mucho dinero', 'prepararse algo importante', 'hacer algo bien', 'organizar algo'.

Construir/ edificar en/ sobre la arena ('hacer algo sin fundamento, sin una base sólida'): 'echar más leña al fuego, estropear más las cosas'.

David y Goliat ('alguien o algo débil contra alguien o algo más fuerte y poderoso'): 'la inteligencia vale más que la fuerza', 'llevarse muy mal', 'más vale maña que fuerza', 'una discusión épica entre dos personas'.

Decisión/ sentencia salomónica ('decisión absolutamente justa'): 'decisión irrelevante que no tiene vuelta atrás'.

Echar margaritas/ perlas a los cerdos ('dar u ofrecer algo valioso o delicado a quien no es capaz de apreciarlo'): 'presumir de algo propio', 'adornar algo que, normalmente, no debería', 'alabarse mucho a sí mismo, quererse a uno mismo', 'insistir en algo cuando es imposible de cambiar', 'no quieras adornar las cosas feas'. El arca de Noé (1. 'lugar lleno de diferentes animales'; 2. 'sitio o cualquier espacio encerrado lleno de muchas cosas diferentes'; 3. 'lugar lleno de mucha gente diferente'; 4. 'medio de salvación'; 5. 'tienda donde se venden muchas cosas diferentes'): 'barco repleto de animales', 'tener un lugar en donde guardas de todo'.

El buen samaritano ('persona caritativa'): 'una persona buena o que se hace pasar por buena'.

El chivo expiatorio ('persona que se chiva de algo'): 'usado para hacer mención a alguien que es muy cotilla'.

El festín/ banquete/ la cena de Baltasar ('comilona exagerada, banquete excesivamente opulento'): 'importante acontecimiento'.

El pan nuestro de cada día ('algo muy acostumbrado, algo que se repite continuamente'): 'cuando agradeces lo que Dios te da cada día de nuestra vida', 'el dinero que se gana', 'la comida diaria'.

Entrar/ meter en el redil ('volver la ambiente en que una comunidad de personas vive acatando unas normas o principios'): 'meterse en un callejón sin salida', 'meterse en algún lío'.

Espada de doble filo ('procedimiento, medio, argumento, etc., que, al ser empleado, puede dar un resultado contrario al que se persigue, o que produce a la vez dos efectos contrarios'): 'para decir que una persona es hipócrita, que tiene dobles intenciones', 'que alguien tiene dos caras', 'algo que hay que usar o manejar con cuidado'.

Estar hecho/ parecer un Adán ('ser desaliñado, muy descuidado en el vestir'): 'ser muy presumido y comportarse como un señorito', 'tener muy buen aspecto', 'ser bestia o primitivo'. 
(Estar en) el camino de Damasco 'arrepentimiento o conversión a otro credo o ideología distintos a los que profesaba'): 'un sendero o camino que parece ser largo'

Gigante/ coloso con pies de barro ('algo que aunque fuerte, sólido, incluso amenazante en apariencia, es muy débil y vulnerable'): 'algo en teoría superior resulta en realidad inconsistente o menos valioso', 'alguien que parece una cosa pero no lo es', 'algo muy grande y con muy poca movilidad', 'proyecto ambicioso pero inestable'.

Hablar adefesios (1. 'hablar en balde'; 2. 'decir tonterías, disparates'): 'decir idioteces', 'hablar mal de algo o alguien', 'decir cosas o palabras malsonantes', 'criticar'.

Ir de Herodes a Pilatos (1. 'ir de una persona a otra'; 2. 'ir de mal en peor en un asunto'): 'conocer a una persona buena o amable y después conocer a una mala'.

La costilla de Adán ('mujer'): 'lo prestado o lo robado', 'eres muy parecido a alguien'.

La oveja descarriada ('persona que se ha apartado del camino moral debido o conveniente'): 'menciona algo perdido y encontrado después'.

La piedra angular ('base o fundamento principal de algo'): 'persona que es modelo o ejemplar'.

La sal de la tierra ('los mejores representantes de la sociedad'): 'algo imprescindible', 'esencia de la vida'.

La torre de Babel (1. 'lugar en que hay gran mezcla de personas de procedencias, aspectos y lenguas diferentes'; 2. 'mezcla de muchas lenguas extranjeras'; 3 . 'situación o lugar donde nadie se entiende'): 'algo muy difícil y trabajoso', 'aplicado a algo grande'.

La voz que clama en el desierto ('alguien que se esfuerza inútilmente por dar consejos o advertencias y no consigue ser escuchado'): 'hablar para nadie', 'como una salvación'.

Llevar alguien su cruz ('soportar con paciencia una prolongada situación desfavorable o un cúmulo de desgracias'): 'cuando tienes una cosa con la cual no estás de acuerdo'.

Llorar lágrimas de sangre ('sentir pena muy viva y cruel'): 'es cuando pierdes la virginidad', 'llorar de rabia', 'no llorar verdaderamente'.

Meterse por el ojo de una aguja ('ser bullicioso y entremetido, introducirse aprovechando cualquier ocasión para conseguir lo que desea'): 'meterse o colarse en algún tema profundamente', 'meterse donde no le llaman', 'pasar por un sitio muy pequeño', 'tratar de engañar sin mucho éxito'.

No ser digno de atarle los cordones de los zapatos ('ser muy inferior a otro; no tener alguien las cualidades físicas, morales o intelectuales de otra persona con la que se le compara'): 'ser digno de lástima probablemente'.

No tener a donde volver la cara ('no hallar auxilio, carecer de todo favor y amparo'): 'estar avergonzado por algo'.

Pagar alguien con las setenas algo ('sufrir un castigo superior a la culpa cometida'): 'una persona es culpada por los errores de otra'.

Pegársele a alguien la lengua al paladar ('no poder hablar (por sed, asombro, susto, etc.'): 'hacer que alguien se calle por ser tan criticón', 'no saber que decir o no decir nada por vergüenza', 'callar la boca a alguien; tragar sus propias palabras', 'una persona que siempre habla mucho, es muy raro que esté callada un rato y entonces se le dice esto'.

Sacar agua de las piedras ('obtener provecho aun de las cosas que menos lo prometen'): 'hablar de cosas pasadas o anteriores', 'aprovechar algo que parece inutilizable'. 
Separar el trigo de la cizaña ('separar lo bueno de lo malo, una cosa de la otra'): 'separar lo bueno de lo malo para quedarse con lo bueno'.

Sepulcro blanqueado ('hipócrita, falso'): 'cuando una persona es hipócrita', 'robar'.

Ser de la piel de Barrabás ('persona malvada, traviesa'): 'una persona en apuros'.

Ser/ parecer un Jeremías (persona que continuamente se está lamentando): 'ser malo, malvado', 'se utiliza cuando alguien acierta alguna "profesía", 'persona que siempre está predicando sus conocimientos y creencias sobre algo'.

Ser/ parecer/ estar hecho una Magdalena ('llorar mucho y desconsoladamente'): 'ser muy blando', 'débil, susceptible'.

Sodoma y Gomorra (1. 'lugar lleno de perversión y vicios'; 2. 'gran confusión y desorden total'): 'algo que es una guasa, un cachondeo de poca vergüenza, poco respetuoso', 'cada uno hace lo que quiere', 'un problema o lío enorme', 'libertinaje', 'algún sitio dode hay una pelea', 'menuda fiesta'.

Subírsele a uno el humo a las narices ('enfadarse', irritarse'): 'ser una persona muy creída'.

Tener los pies de barro ('ser vulnerable'): 'caminar en falso'.

Traer a alguien por la calle de amargura ('causar muchos disgustos'): 'cuando una persona siente preocupación por otra', 'enfadar a alguien'.

Valle de lágrimas ('lugar lleno de sufrimientos, penas, etc. (generalmente referido al mundo)'): 'una persona que llora y sufre mucho', 'lugar donde hay muchas personas llorando', 'época muy mala para una persona', 'algo que puede causar muchos problemas'.

Ver el cielo abierto ('presentársele ocasión o coyuntura favorable para salir de un apuro o conseguir lo que deseaba'): 'ser libre para hacer lo que se quiere', 'ver todo claro'.

Ver la paja en el ojo ajeno ('darse cuenta de los defectos de los demás y no darse cuenta de los propios, que son mayores'): 'tener envidia de algo/ alguien'.

Los resultados de la encuesta realizada en la Universidad de Granada con estudiantes españoles demuestran que los alumnos a menudo desconocen el significado de las expresiones de su lengua materna, aun así, intentan interpretar el significado a partir de la imagen subyacente y sus asociaciones léxico-cognitivas, por lo cual algunas respuestas resultan bastante curiosas.

\subsection{Encuesta realizada en la Universidad de Kazán}

Ahora nos gustaría presentar los resultados de una encuesta que ha sido realizada con 44 alumnos rusos del $1^{\circ}, 2^{\circ}$ y $3^{\circ}$ (17-22 años) de filología española en la Universidad de Kazán.

Para la encuesta, han sido escogidas 9 unidades fraseológicas españolas de origen bíblico que los alumnos no conocían debido al nivel elemental-intermedio de su conocimiento de la lengua española, incluso, les hemos facilitado la traducción literal de éstas: arca de Noé, vacas flacas, gigante con pies de barro, pan de cada día, hecho un Adán, donde Sansón perdió el flequillo, sal de la tierra, meterse por el ojo de una aguja, bañarse en el/ ir al río Jordán. Todas estas UFB son idiomáticas icónicas sin ningunas anomalías gramaticales ni léxicas. Además, hemos elegido, por una parte, algunas UFB que son frecuentemente usadas en español y las que menos, y, por otra parte, unas UFB que tienen correspondencia en ruso y las que no. La tarea que se les planteó fue la siguiente: intentar explicar en ruso los significados de las unidades fraseológicas propuestas a partir de la imagen subyacente en su base y dar, cuando sea posible, ideas asociadas con ellas. Lo que pretendemos averiguar con esta encuesta es lo siguiente: cómo se procesan las UFs idiomáticas a partir de la imagen desde el punto de vista cognitivo, en qué medida influye el conocimiento cultural en 
la interpretación del significado de las UFs y si existe interferencia con la lengua materna a la hora de interpretar el significado de la UF.

Se han dado en total 385 respuestas de las 396 posibles (44 alumnos por 9 UFB) y 11 casos sin respuesta. Sorprendentemente, se han manifestado casos, aunque muy escasos, de no entender lo que es el significado figurativo. Este hecho ha generado respuestas, algunas muy anecdóticas, como, por ejemplo, arca de Noé 'lugar donde se escondieron los animales durante el diluvio universal'; vacas flacas 'vacas muy feas'; vacas flacas 'vacas graciosas (que dan risa)'; donde Sansón perdió el flequillo 'lugar donde Sansón quedó calvo, el Chernobyl'; ir al/ bañarse en el río Jordán 'ir y nadar en el río'. En cuanto al reconocimiento del origen de las UFB, algunos estudiantes han indicado el origen bíblico de algunas de las frases, incluso, explicando los episodios de la Biblia que han dado origen a una u otra UB, lo que indica muy buen conocimiento de la Biblia por parte de algunos alumnos que pueden ser creyentes practicantes. Cabe mencionar hasta algunas respuestas folclóricas: por ejemplo, la existencia de la sal de la tierra se debe a que Jesús derramó las lágrimas a la tierra que las absorbió.

A la hora de explicar los significados de las UFB, los estudiantes han empleado combinaciones de palabras o estructuras oracionales, algunas veces empezando por cuando, o no siempre han mantenido la categoría gramatical de la UFB (por ejemplo, explicando una UFB adverbial mediante estructura verbal, etc.). En algunos casos, los estudiantes han puesto más de una definición, admitiendo varias posibilidades de interpretación semántica. Asimismo, es interesante señalar que en algunos casos los estudiantes han puesto otras unidades fraseológicas rusas, que creen ser sinonímicas o equivalentes, para definir las UFB en cuestión. Así, por ejemplo, la UFB arca de Noé ha sido definida como каждой твари по паре "una pareja de cada ser vivo"; gigante con pies de barro - замок из песка "castillo de arena", c Ахилесовой пятой "con el talón de Aquiles"; pan de cada día - насущный хлеб "pan substancial"; donde Sansón perdió el flequillo - на кудыкиных горах "en las montañas de *kudyka"; sal de la tierra - nуn земли "ombligo del mundo"; ir all bañarse en el río Jordán - возродиться как Феникс из пепла "renacer como el Fénix de las cenizas".

A continuación vamos a comentar las respuestas correspondientes más detalladamente.

\section{1. arca de Noé}

Casi todos los encuestados conocen la historia bíblica del diluvio universal y del arca de Noé. Todas las respuestas se pueden reducir a los siguientes grupos: salvación o lugar de salvación; lugar de refugio; lugar lleno de gente o animales; multitud de gente o animales.

Entre otras respuestas, digamos "individuales", que se han dado, encontramos 'barco de salvación', 'lugar donde todos los seres vivos se juntan en parejas' que realmente lo era el arca de Noé, 'creación de la Tierra', 'castigo de Dios', 'situación extrema en la que una persona ha de sobrevivir', 'solidaridad' que parecen ser más bien asociaciones que definiciones, 'la última esperanza' que de algún modo está vinculado a la idea de salvación, 'lugar donde hay muchas cosas valiosas'. En el último caso, parece que la persona encuestada no conoce la historia bíblica; aunque tal vez esta interpretación esté determinada por la asociación de la palabra arca - ковчег con 'caja', ya que tanto en español como en ruso existe el término religioso el arca de la Alianzal del Testimonio - ковчег завета/ откровения 'aquella en que se guardaban las Tablas de la Ley, el maná y la vara de Aarón'. Entre las curiosidades, encontramos las respuestas como 'lugar donde no existe el mal ni el dolor, donde 
todos están bien y son felices; una casa perfecta con todas las comodidades' o 'lugar para reuniones o solución de cuestiones importantes'.

\section{2. vacas flacas}

La mayoría de los encuestados no asocian la UFB con la Biblia, sólo dos personas han señalado su origen bíblico. Por lo tanto, se reconstruye un escenario distinto: un grupo de vacas flacas que no tienen nada que comer y que no dan ni carne ni leche a sus dueños. No es normal que las vacas sean flacas, por lo cual todos los encuestados perciben la expresión como algo negativo. El razonamiento de los estudiantes encuestados es bastante lógico. Así, algunos alumnos demuestran cierto grado de pragmatismo: como las vacas flacas no dan ni carne ni leche son inútiles, de ahí el significado que le atribuyen a la UFB 'cosa, persona inútil'. Si las vacas son flacas, le puede faltar comida a la gente, de ahí 'comer mal', 'falta de comida a la gente', 'hambre', 'gente hambrienta', 'los seres vivos que comen poco o viven en condiciones muy malas y no tienen posibilidad de comer mucho', lo cual también se asocia con la 'pobreza, miseria, ruina absoluta', 'los pobres', con el significado más concreto 'negocio que no trae beneficio' o, incluso, percibida literalmente la UFB, 'índice de la situación económica del dueño de las vacas'. Entre las definiciones encontramos también 'las tierras infértiles' que lógicamente también pueden ser la causa de la falta de alimentación para las vacas. Unos pocos estudiantes han interpretado la UFB como semiidiomática, conservando el adjetivo su significado literal, lo que, así como el significado vulgar de la palabra корова 'vaca' en ruso 'una mujer gorda y torpe', les ha llevado a la conclusión que las vacas flacas son 'chicas muy flacas que probablemente están de régimen' o 'mujer hambrienta que apenas puede estar de pie y que no ha comido nada, posiblemente ha trabajado todo el día'. Muy pocos encuestados la relacionan con 'desgracia' o 'mal augurio', incluso una persona ha puesto 'muerte'. Entre las respuestas curiosas, difíciles de explicar, se hallan 'no capaz', 'una persona estúpida que tarda mucho en pensar' y 'la situación en la que la esencia de algo o alguien no corresponde con lo que se dice de algo o alguien'. Aunque en el último caso la alumna explica su lógica de la siguiente manera: "una vaca ha de ser sana, por eso una vaca flaca ya no es una vaca, no es una vaca de verdad".

\section{3. gigante con pies de barro}

Solamente una alumna ha indicado el origen bíblico de la UFB, describiendo la situación que la ha generado. La mayoría de los encuestados parecen haber razonado de la siguiente manera: gigante es algo grande, importante o alguien importante, fuerte, poderoso; pies son base, fundamento; barro es algo débil, frágil, inestable. Todo eso les lleva a la conclusión que la UFB puede significar, generalizando, 'algo inseguro, sin base, fundamento sólido', 'vulnerabilidad de una persona aparentemente fuerte y poderosa', 'falsa apariencia'. Varios alumnos creen que la UFB designa a 'una persona torpe', porque con los pies de barro es difícil andar. Una estudiante concluye que se trata de 'una persona discapacitada'. Para algunos, es 'algo innatural que contradice las normas aceptadas' o 'una cosa grande e inútil'. Son difíciles de explicar las siguientes respuestas: 'una persona que con seguridad está llegando a su meta, una persona terca', 'una persona que está parada en un punto, no percibe el mundo alrededor, insiste firmemente en su opinión', 'una persona de gran corazón y alma pura', 'persona que pisa firme la tierra, está segura de sí misma'. Sin embargo, el significado contrario 'una persona que no tiene los pies bien anclados en la tierra' que aparece en una de las respuestas parece más justificado por la imagen subyacente. Entre otras respuestas curiosas individuales, encontramos 'maquina enorme mal construida que puede derrumbarse en cualquier momento', 'una persona 
que lo destruye todo o hace algo incorrectamente o le sale todo mal', 'petrificado', 'gracioso, ridículo'.

\section{4. el pan de cada día}

En ruso, la palabra хлеб "pan" se usa metafóricamente como "comida, mantenimiento' y 'medios de existencia, ganancias'. Cabe señalar que también en español, según el DRAE (acepción 4), pan es 'todo aquello que en general sirve para el sustento diario'. Parece que está acepción ha influido en la interpretación global de la UFB, por eso encontramos las respuestas como 'comida', 'trabajo que trae beneficios', 'ganancias', 'lo más importante y necesario para vivir', inclusive, 'personas y objetos sin cuales la vida no se ve posible'. Una persona encuestada desarrolla la siguiente explicación: "pan que se gana cada día con gran labor, "pan" puede ser cualquier objetivo o asunto que es muy importante para una persona pero difícil de conseguir, por eso el resultado es muy esperado y valioso'. Además, pan de cada día es algo que da 'seguridad para el día de mañana'. La combinación de palabras cada día les lleva a los alumnos a pensar que es 'algo trivial, que carece de interés', 'imagen de la vida de una persona aburrida, limitada en su desarrollo e intereses', 'algo que se nos concede cada día', 'uno puede hartarse de hacer cada día lo mismo', 'cotidianidad; constancia' y, finalmente, tres alumnos dan con el significado de la UFB española 'cada día ocurre lo mismo', aunque también es posible que conozcan la expresión española. Una alumna relaciona la frase con la historia bíblica del milagro de los panes y peces, por lo cual interpreta la UFB como 'algo que no desaparece, no se agota, queda cada día'. Son difíciles de explicar las siguientes respuestas: 'aspiración de ser independiente', 'un verdadero amigo que siempre te ayudará y en quien puedes confiar'.

\section{5. hecho un Adán}

Según los encuestados, Adán poseía las siguientes características que se han plasmado en el significado de la UFB: 'guapo' (quizás, confundiendo con otro personaje mitológico Adonis), 'perfecto', 'desnudo', 'ingenuo', 'puro'. Casualmente, encontramos las respuestas como 'alto', 'tonto', 'inteligente', 'noble'. Como era el primer hombre, aparecen las respuestas muy lógicas 'ser primero en algo, descubridor'. Entre las respuestas interesantes razonadas hallamos 'apocamiento (falta de carácter), no tener uno su propia opinión', ya que Adán ha sido seducido por Eva a comer la manzana; 'sufrir una tentación', 'caer en las tentaciones', 'no poder resistir', 'cometer algo malo, un pecado', 'pecador', porque Adán ha probado la fruta prohibida; 'no tener nada (ni dinero, ni ropa, ni casa), recibir todo fácilmente sin ningún esfuerzo', 'ser una persona feliz, sin obligaciones; una persona que disfruta de la vida, optimista, que ve la belleza en todo', puesto que Adán vivió en el Paraíso antes de cometer el pecado. Nos parece bastante original la respuesta 'una persona infame' "porque echó la culpa a Eva", como explica una alumna. Entre otras respuestas encontramos 'estar solo' 'ser verdadero hombre', 'varón', 'compartir todas las desgracias con una persona cercana', 'sacrificio por algo muy importante; algo bueno que no existía antes'. Como vemos, ni una respuesta ha dado con el significado de la UFB española, puesto que es opaca.

\section{6. donde Sansón perdió el flequillo}

La mayoría de los encuestados parecen conocer la historia de Sansón y Dalilah. Al responder, sólo el $34 \%$ de los encuestados se referían a un lugar, empleando en las definiciones los elementos lugar, donde o usando adverbio de lugar u otra unidad fraseológica adverbial. Sólo una alumna ha dado con el significado de la UF española, empleando la definición 'muy lejos'. Dos han respondido 'lugar difícil 
de encontrar' que es semánticamente cercano al significado de la UFB en cuestión. Son muy lógicas las respuestas 'lugar donde alguien ha perdido algo', 'lugar donde una persona deja una parte de sí misma que es realmente importante para ella', 'lugar donde sucedió algo malo después de que la vida ha cambiado radicalmente', 'lugar de traición; cede de los enemigos', 'lugar de lucha'; menos motivadas 'donde se esconde la verdad', 'lugar de supervivencia', 'lugar conocido donde uno ya ha estado' y un disparate total de asociación de ideas 'lugar donde Sansón quedó calvo, el Chernobyl'. La mayoría de los encuestados definan la UFB como 'perder poder, fuerza' que refleja muy bien los hechos narrados en la Biblia, o, casualmente, más generalizado 'perder un cosa importante'. Asimismo, son lógicas las respuestas 'recibir un golpe por la espalda, cuando uno traiciona a la persona cercana', 'encontrar un punto débil'. Varias alumnas, de manera algo machista, han asociado la UFB con los asuntos amorosos, la malicia y la culpa de las mujeres. Entre las curiosidades podemos mencionar la respuesta 'pruebas (de crimen)', ya que, según la encuestada, Sansón perdió una prueba en el lugar del crimen.

\section{7. sal de la tierra}

La sal constituye un elemento muy importante en la vida humana, no sólo es lo que condimenta la comida, sino también participa en los procesos fisiológicos de un ser humano. En los tiempos antiguos, la sal era algo muy valioso. Conociéndolo, muchos de los encuestados han optado por las respuestas 'lo más importante', 'la esencia de algo', 'algo valioso' o, inclusive, 'comienzo de problemas, comienzo de todo', 'el origen, la esencia de algún problema', 'lo que forma la base la algo', 'origen de algo', 'la verdad'. Además, para uno de los encuestados, la UFB significa 'cosa difícil de conseguir; algo místico, algo interesante que quieres ver, probar, sentir, etc.'. Tres de los encuestados han relacionado la expresión con otra UFB internacional ombligo del mundo refiriéndose a una persona más importante o que se cree serla. Cerca del significado real de la UFB, queda la respuesta 'personas mundanas, famosas'. Por otra parte, algunos encuestados asocian la sal (en exceso), como es amarga, con 'aflicción', 'una parte importante de la Tierra, pero que trae dolor y sufrimiento a la gente', 'las cosas trágicas o tristes', 'dificultades; mala cosecha; adversidades vividas por una persona', 'algo que lo estropea todo un poco'. Sin embargo, si se añade un poco de sal a la comida, ésta se hace deliciosa, por lo tanto sal de la tierra significa, según una alumna, que 'todo lo malo puede convertirse en bueno'. Cabe mencionar que en ruso la palabra соль 'sal' se usa en sentido metafórico 'algo que le añade un sentido particular, interés, algo picante a la vida', lo que les ha llevado a muy pocos encuestados admitir que es la UF española debería significar 'algo que le añade gracia a la vida', 'interés de la vida'. La respuesta 'sabiduría popular' también está relacionada con uno de los significados del lexema sal: 'agudeza'. Entre las curiosidades, encontramos las respuestas 'arena dorada (aurífera)', 'azúcar', 'minerales' o la UF rusa c миру по нитке "un hilo de todo el mundo" "un poco de todo el mundo'. En el último caso la alumna parece asociar la sal con poca cantidad.

\section{8. meterse por el ojo de una aguja}

Nadie de los encuestados ha relacionado la UFB con la Biblia. Todas las respuestas se basan en la idea que para meterse por el ojo de una aguja hay que 'ser sagaz, perillán, mañoso, muy hábil' y el ojo de una aguja se interpreta como algún apuro, lío, situación muy difícil, sin salida, de ahí también las respuestas 'salir de apuros', 'salir de una situación difícil', 'superar las dificultades', etc. Además, el mismo hecho de meterse por el ojo de una aguja les parece a los alumnos una tarea algo imposible, extraordinaria de realizar: 'hacer algo imposible', 'hacer algo 
extraordinario' que también refleja de algún modo el sentido bíblico. Entre otras respuestas con distintos matices semánticos, encontramos 'sufrir penalidades para conseguir algo bueno', 'hacer todo lo posible para conseguir un objetivo', 'hacer algo actuando con astucia', 'salvarse de un peligro de milagro', 'ser vivaracho, tener tiempo para todo', 'estar invisible' o 'meterse en cualquier sitio intransitable' entendido casi literalmente.

\section{9. bañarse en el/ ir al río Jordán}

Los alumnos parecen no conocer la historia de Naam, porque realmente no figura entre las historias bíblicas más conocidas. Sin embargo, la relacionan con el bautizo de Jesucristo en el Jordán considerado sagrado, lo que le ha llevado a una alumna a la conclusión que es 'bautizarse', y a otra conclusión casi unánime que la UFB significa 'purificarse', 'expiar los pecados', puesto que el agua, sobre todo bendecida, según las creencias de muchos pueblos, se considera tener un poder purificante sobre un ser humano. Algunos encuestados asocian el río Jordán con algo extraordinario, milagroso, bendecido que trae suerte y felicidad: 'hacer algo extraordinario', 'ver el milagro', 'recibir bendición en un sitio sagrado, protección del patrón celestial' 'recibir la bendición, permiso para hacer algo', 'tener suerte, felicidad en cualquier asunto', 'bañarse en la felicidad'. Las respuestas 'iniciarse en algo, probar algo', 'pasar una prueba antes de empezar un asunto' podrían estar asociadas con la UF rusa пройти (сквозь) огонь, воду (и медные трубы) "pasar (por) el fuego, el agua (y los tubos de cobre)" "experimentar mucho en la vida, hacerse experimentado', con la idea de que el agua, igual que el fuego, es una fuerza de la naturaleza que pone a prueba a un ser humano. En el caso de la respuesta, empleando la UF rusa выйти сухим из воды "salir seco del agua" 'salir impune', es evidente la asociación de ideas río - agua. Es difícil de explicar el razonamiento que ha seguido la alumna de la respuesta 'conocer que te han engañado; sorprenderse uno de que lo haya traicionado una persona en quien confiaba'. Las respuestas 'trompeta de Jericó, el muro de llanto' parecen ser nada más que asociaciones de imágenes, ya que no explican nada. En el caso de la respuesta 'el río de la muerte, la persona que se ha metido en él está muerta', la persona encuestada evidentemente está confundiendo con otro río de la mitología clásica griega. Sólo una persona encuestada parece acertar el significado de la UFB española, habiendo puesto 'renacer (como el Fénix de las cenizas), rejuvenecer'.

\section{A modo de conclusión}

El estudio de la fraseología desde la dimensión cultural cada vez adquiere más importancia, puesto que permite descubrir lo específico en distintas lenguas y distintas culturas. Los fenómenos culturales que se reflejan en la fraseología engloban aspectos históricos y sociales de la cultura, aspectos de la cultura material, fenómenos intertextuales (citas y alusiones), dominios conceptuales ficticios y símbolos culturales. Además de las unidades fraseológicas propias de la lengua y de la cultura en cuestión, se puede destacar el grupo de las unidades fraseológicas préstamos en sentido amplio, es decir, las que reflejan los fenómenos de la cultura ajena. Este último grupo comprende también las frases hechas de origen bíblico.

En cuanto a la interpretación del significado de las frases hechas marcadas culturalmente, uno de los factores más importantes es el nivel cultural de los alumnos: en ciertos casos el conocimiento de la Biblia ha permitido establecer el vínculo motivacional necesario entre la imagen subyacente y el significado de los bibleísmos fraseológicos. Otro factor es el carácter analizable y descomponible de las frases hechas: ha sido más fácil interpretar las expresiones semánticamente descomponibles. La interferencia de la lengua materna, es decir, la existencia de un equivalente 
fraseológico en la lengua materna y su conocimiento por parte de los alumnos, también influye en la interpretación del significado. Otro factor tiene que ver con las características individuales de cada informante con su propio mundo asociativo y desarrollo intelectual.

\section{Referencias}

ARIZA, M. 1990. Religión y lenguaje. En: Jornadas de Filología. Profesor Francisco Marsa. Barcelona, Universitat de Barcelona, p. 17-29. ISBN 8478753265

BARANOV, A. - DOBROVOL'SKIJ, D. 2009. Aspectos teoricos da fraseoloxia. Santiago de Compostela, Xunta de Galicia. ISBN 9788445348383

BIRIX, A.K. - MOKIENKO, V.M. - STEPANOVA, L.I. 1998. Slovar' russkoi frazeologii. Istoriko-etimologicheskii spravochnik. Spb.: Folio-press. ISBN 5288021325

BUITRAGO, A. 2007. Diccionario de dichos y frases hechas, reed. Madrid, Espasa. ISBN 9788467025019

CACCIARI, C. - TABOSSI, P. (eds.). 1993. Idioms: Processing, Structure, and Interpretation. New Jersey, London, Erlbaum. ISBN 0805810382

CELDRAN GOMARIZ, P. 2004. Diccionario de frases y dichos populares: comparaciones, ocurrencias, personajes y criaturas populares del folclore, la historia menor y la leyenda. Madrid, Alderabán. ISBN 849541435X

COWIE, A. (ed.). 1998. Phraseology: Theory, Analysis and Applications. Oxford: Oxford University Press. ISBN 0198299648

DOBROVOL'SKIJ, D. 1998. Nacional'no-kul'turnaya specifika vo frazeologii. En: Voprosy yazykoznaniya, 6, S. 48-57. ISSN 0373658X

DOBROVOL'SKIJ, D. - PIIRAINEN E. 2000. Sobre los símbolos: aspectos cognitivos y culturales del lenguaje figurado. En: Pamies Bertrán y Luque Durán (eds.), p. 29-54. ISBN 8479331607

DOBROVOL'SKIJ, D. - PIIRAINEN E. 2005. Figurative language: cross-cultural and cross-linguistic perspectives. Amsterdam, Elsevier. ISBN 0080438709

DOBROVOL'SKIJ, D. - PIIRAINEN E. 2006. Cultural knowledge and idioms. En: IJES, International Journal of English Studies, Vol. 6, 1, p. 27-42. ISSN 1578-7044

GIBBS, R. 1993. Why idioms are not dead metaphors. En Cacciari y Tabossi (eds). (1993), p. 57-77. ISBN 0805810382

GIBBS, R.W. et al. 1989. How to kick the bucket and not decompose: Analyzability and idiom processing. En: Journal of Memory and Language, 28, p. 576-593. ISSN 0749596X

IRIBARREN, J.M. 1994. El porqué de los dichos. Sentido, origen y anécdota de los dichos, modismos y frases proverbiales de España con otras muchas curiosidades. Pamplona, Departamento de Educación y Cultura. ISBN 8423511804

JUNCEDA, L. 1998. Diccionario de refranes, dichos y proverbios. Madrid, Espasa. ISBN 8423994260

LUQUE DURÁN J. DE D. 1996. Tipología léxica y tipología fraseológica: universales y particulares. En: Luque Durán y Manjón Pozas (eds.), p. 139-153. ISBN 8479339586

LUQUE DURAN J. DE D. 2007. La codificación de la información lingüísticocultural en los diccionarios (inter)culturales. En: Luque Durán y Pamies Bertrán (eds.), p. 329-373. ISBN 9788479334835

LUQUE DURAN J. DE D. - MANJON POZAS, F.J. (eds.) 1997. Estudios de lexicología y creatividad léxica (Terceras Jornadas Internacionales sobre estudio y enseñanza del léxico "In memoriam Leocardio Martín Mingorance, Granada, 1996). Granada, Granada Lingvistica. ISBN 8479339586 
LUQUE DURAN J. DE D. - PAMIES BERTRAN, A. (eds.). 2005. La creatividad en el lenguaje: colocaciones idiomáticas y fraseología, Granada, Método. ISBN 847933312X

LUQUE DURÁN J. DE D. - PAMIES BERTRÁN, A. (eds.) 2007. Interculturalidad y lenguaje (I): El significado como corolario cultural. Granada, Granada Lingvistica / Método. ISBN 9788479334835

LUQUE NADAL, L. 2009. Los culturemas: ¿unidades lingüísticas, ideológicas o culturales? En: Language Design: Journal of Theoretical and Experimental Linguistics, 11, p. 93-120. ISSN 11394218

MOKIENKO, V.M. 2005. Intertextemas y texto en las lenguas eslavas. En: Luque Durán y Pamies Bertrán (eds.), p. 175-187. ISBN 847933312X

PAMIES BERTRÁN, A. 2002. Modelos icónicos y archimetáforas: algunos problemas metalingüísticos en el ámbito de la fraseología. En: Language Design: Journal of Theoretical and Experimental Linguistics, 4, p. 9-19. ISSN 11394218

PAMIES BERTRAN, A. 2007. El lenguaje de la lechuza: apuntes para un diccionario intercultural. En: Luque Durán y Pamies Bertrán (eds.), p. 375-404. ISBN 9788479334835

PAMIES BERTRAN, A. - LUQUE DURAN, J.DE D. (eds.). 2000. Trabajos de lexicología y fraseología contrastivas. Granada, Método. ISBN 8479331607

REAL ACADEMIA ESPAÑOLA. 2001. Diccionario de la lengua española [Recurso electrónico disponible en la Red: www.rae.es].

SOLER-ESPIAUBA, D. 1990. Impacto del fenómeno religioso en el español coloquial. En: Actas del Congreso de la Sociedad Español de Lingüística, XX Aniversario, vol. II. Madrid, Gredos, p. 769-786. ISBN 84249143376

SOLODUXO, E.M. 1989. Teoriya frazeologicheskogo sblizheniya (na materiale yazykov slavyanskoi, germanskoi i romanskoi grupp). Kazan', Izd-vo KGU. ISBN 5746400408

TELIYA, V. - BRAGINA, N. - SANDOMIRSKAYA, I. 1998. Phraseology as a Language of Culture: Its Role in the Representation of a collective Mentality. En: Cowie (ed.) (1998), p. 55-75. ISBN 0198299648

TELIYA, V.N. 1996. Russkaya frazeologiya: semanticheskii, pragmaticheskii i lingvokul'turologicheskii aspekty. M.: Shk. «Yazyki rus. kul'tury».. ISBN 5887660473

WOTJAK, G. 2007. Algunas reflexiones acerca de lengua y cultura. En: Luque Durán y Pamies Bertrán (eds.), p. 213-234. ISBN 9788479334835

Words: 8965

Characters: 55863 (31,04 standard pages)

Assoc. Prof. Anna Zholobova, PhD

Department of Romance Philology

Lev Tolstoy Division of Russian and Foreign Philology

Institute of Philology and Intercultural Communication

Kazan Federal University

Kremlevskaya, 18

420008 Kazan

Russia

anijola@yahoo.es 